\title{
Effects of Game Based Weight-Bearing Training on Lower Extremity Muscle Activation and Balance in Stroke Patients
}

\author{
Dae-jung Yang'1, Seung-Kyu Park', Jeong-II Kang', Je-Ho Kim¹, Dae-Keun Jeong', Jong-Uk Choi² \\ 'Department of Physical Therapy, Sehan University; ${ }^{2}$ Department of Physical Therapy, Graduate School, Sehan University, Yeongam-gun, \\ Jeollanam-do, Korea
}

\begin{abstract}
Purpose: Theobjective of this study was to determine the effects of game based weight-bearing training (GBWB) on lower extremity muscle activation and balance in stroke patients.

Methods: Thirtysubjects were randomlydividedinto two groups: experimentalgroup I $(n=15)$ and controlgroup II $(n=15)$. Each group was providedinterventionunder two conditions, as follows: in the Gamebased weight-bearing training (groupI), 30 minutes per day, five times per week, with physical therapy for 30 minutes, and in the functional weight-bearing training (groupII),30 minutes per day, five times per week, with physical therapy for 30 minutes The training program was conducted for a period of eight weeks. Sulote were measured on lower extremity muscle (rectus femoris, biceps femoris, tibialis anterior, gastrocnemius)by electromyographyand balance by Biorescue. ANCOV as performedfor comparisonof lower extremity muscle activation and balance between different intervention methods. All patients were evaluated at baseline and at the end of the treatment protocol.Statistical significance was tested between the patients before and after treatment by $\mathrm{t}$-test.

Results: Significant difference in lower extremity muscle activation was observed in experimentalgroup I compared with control group II ( $\mathrm{p}<0.05)$. Significant difference in balance was observed in experimental group I compared with control group II $\varangle$ p.001).

Conclusion: Findingsof this study suggest that game based weight-bearing training may have a beneficial effect on improvementof lower extremity muscle activation and balance in stroke patients.
\end{abstract}

Keywords: Stroke, GBWB, Muscle activation, Balance

\section{서 론}

뇌졸중 환자들은 운동기능과 감각기능, 인지기능 등에 손상을 보이 고, 그 중 운동기능의 손상은 대뇌겉질 흥분성 감소와 비사용으로 인 한 근육 특성의 변화 등 다양한 원인에 의해 근약화를 유발하며 운 동단위 수와 운동단위 발화율에 감소를 보이며 약화된 뇌졸중 환자 의 근력은 균형과 높은 상관관계를 보인다. ${ }^{1-3}$ 균형은 지지면 안에 중 력 중심(center of gravity, COG)을 위치하도록 하는 자세 안정성을 유 지하는 능력으로 정적인 자세를 유지하는 정적인 균형과, 동적인 움 직임 동안 인체중심점을 조절하는 동적인 균형으로 나뉜다. 뇌졸중 환자들은 비슷한 연령대의 정상인과 비교했을 때 선 자세에서 안정 성 한계가 감소되며, 자세동요가 증가하였고 일상생활에 어려움을 초래하였다.5 뇌졸중 환자의 자세동요 증가는 비대칭적인 체중지지 와높은 상관관계를 보였다.7.8
뇌졸중으로 인한 반마비 환자들은 비대칭적인 체중지지로 인해 비 마비측의 과도한 체중지지를 보이고 마비측 하지의 질량 중심의 이동이 어렵기 때문에 기능적인 활동에 제한을 보인다.910 신체 질량 중심의 이동과 위치 조절은 복잡한 신경근의 활동을 필요로 하며, 반 마비 환자들은 각 근육들의 협응능력이 감소되고, 각 관절에서의 충 분한 근육의 활성을 만들지 못하기 때문에 비 대칭적인 체중지지율 이 증가된다."1 반마비 환자들의 비대칭적인 체중지지는 낙상의 위험 도를 증가시키며 보행, 계단 오르기(stair climbing), 일어서기 동작(sit to stand), 돌기(turning) 등과 같은 기능적 활동에 영향을 주어 일상생 활동작과 사회적인 활동 참여 제한으로 삶의 질을 감소시킨다. ${ }^{12}$ 최 근 반마비 환자들의 일상생활 동작 및 낙상에 의한 부상 위험을 최소 화하기 위해 체중지지 훈련이 중재되고 있다. ${ }^{13}$

뇌졸중 환자에게 대칭적인 체중지지 훈련은 앉은자세에서 일어나 기 동작 수행 시 근력의 증가와 양쪽 다리의 대칭적인 체중지지율의
Received Jul 23, 2015 Revised Aug 16, 2015

Accepted Aug 18, 2015

Corresponding author Jong-Uk Choi

E-mail 1031yes@naver.com
Copylight(C)2015 The Korea Society of Physical Therapy

This is an Open Access article distribute under the terms of the Creative Commons Attribution Non-commercial License (Http:// creativecommons.org/license/by-nc/3.o.) which permits unrestricted non-commercial use, distribution, and reproduction in any medium, provided the original work is properly cited. 
증가 및 압력중심(center of pressure, $\mathrm{COP}$ )의 동요감소에 효과적이었 다. ${ }^{14}$ 또한 뇌졸중 환자에게 체중이동 훈련은 버그균형평가의 향상과 똑바로 선 자세를 유지하는 동안 압력중심의 동요면적과 동요속도가 감소되어 체중지지 훈련이 자세조절 능력을 향상시킨다고 하였다. ${ }^{15}$ 하지만 체중지지 훈련은 생체 되먹임의 부족과 환자의 동기부여에 결 여로 운동학습과 운동조절에 어려움을 보이기 때문에 최근 게임 기 반 재활훈련의 필요성을 시사하였다. ${ }^{16}$

게임 기반 재활훈련은 뇌졸중 환자의 근력과, 관절가동범위, 운동 속도 그리고 협응력을 증진시키는 데 효과적이며 생체 되먹임을 통 해 운동 조절능력을 향상시키고 동기부여를 통해 환자의 지속적인 연습을 가능하게 하였다.1718 게임기반 재활훈련 중재는 뇌졸중 환자 의 균형능력과 이동능력 및 앉은자세의 동적 균형능력 향상에 유의 한 증가를 보였다. ${ }^{19,20}$

최근 게임 기반 재활훈련을 중재한 후 효과에 대한 연구는 활발하 게 이루어지고 있으나, 대부분의 선행연구들은 훈련 프로그램이 스 포츠 운동과 같은 큰 동작으로 구성되어 있어 균형능력에 저하를 보 이는 뇌졸중 환자에게 잘못된 자세 조절 전략(strategy)을 학습할 수 있기 때문에 환자들의 특성에 맞는 적절한 훈련이 요구된다. ${ }^{16}$ 이에 본 연구의 목적은 뇌졸중 환자에게 정량적인 균형능력 측정을 통한 게임 기반 체중지지 훈련을 중재하여 다리 근활성도와 균형에 미치 는 영향에 대해 알아보고 뇌졸중 환자의 재활에 기초자료를 제공하 고자한다.

\section{연구방법}

\section{1. 연구대상}

본 연구는 뇌경색이나 뇌출혈로 인해 반마비 진단을 받고 0-12개월 이하의 뇌졸중 환자 30 명을 대상으로 전남 소재의 J병원에서 재활치 료를 통해 기능회복을 하고자 입원한 환자들 중 실험방법에 대해서 충분하게 설명을 듣고 자발적인 참여의사를 밝히고 동의한 환자를 선정하였다. 세부적인 선정기준은 $10 \mathrm{~m}$ 이상 독립적인 보행이 가능한 자, 실험에 영향을 줄 수 있는 내외과적 의학적 질환을 가지고 있지 않은 자, 신경학적 검사로 청각, 전정, 안구 손상이 없는 자, 편측무시 증상이 없는 자, 한국형 간이 정신상태 검사(MMSE-K) 점수가 24점 이상으로 의사소통이 가능한자로 선정하였다(Table 1).

\section{2. 실험방법}

본 연구는 게임기반 체중지지 훈련군(Group I) 15명, 기능적 체중지지 훈련군(Group II) 15 명으로 각각 무작위 임의 선정하였으며, 각각의 중재는 8 주간 주 5 회 일 30 분 중재한 후 중재 전후 마비측 다리의 근 활성도와안정성 한계를 측정하여 분석하였다.
Table 1. General characteristic of subjects

\begin{tabular}{lcc}
\hline & $\begin{array}{c}\text { Group I }(n=15) \\
\text { Mean } \pm \text { SD }\end{array}$ & $\begin{array}{c}\text { Group II }(n=15) \\
\text { Mean } \pm \text { SD }\end{array}$ \\
\hline Height $(\mathrm{cm})$ & $1.6 \pm 5.1$ & $1.6 \pm 4.2$ \\
Age (year) & $6.1 \pm 5.5$ & $6.0 \pm 5.8$ \\
Weight (kg) & $6.7 \pm 6.0$ & $6.8 \pm 6.2$ \\
Stroke duration (month) & $4.8 \pm 1.2$ & $5.2 \pm 1.4$ \\
Type (infarction/hemorrhage) & $8 / 7$ & $7 / 8$ \\
Paretic side (left/right) & $8 / 7$ & $8 / 7$ \\
\hline
\end{tabular}

Group I, game based weight-bearing training (GBWBT); Group II, functional weight-bearing training (FWBT).

\section{1) 게임기반 체중지지 훈련}

본 연구에서는 게임을 기반으로 체중지지 훈련을 위해 균형능력의 정량적인 측정과 게임을 기반으로 하는 체중지지훈련을 할 수 있도 록 고안된 Biorescue (RM Ingenierie, Rodez, France)를 이용하였다. Biorescue는 이동이 손쉬운 사각형의 힘판(Force plate)과 자료 분석용 컴 퓨터와 데이터 및 측정과 훈련방법을 시각적으로 제공하는 모니터로 구성되어 있으며 훈련 시 되먹임을 제공한다. 훈련 전 대상자는 정량 적 균형능력 평가인 안정성한계를 측정한 후 균형능력 수준에 맞는 적절한 난이도의 훈련을 실시하였다. 훈련은 카드 맞추기(card select), 스키타기(skijoring), 미로찾기(maze problem), 자동차 장애물 피하기 (car obstacle avoidance), 유리관 비율 맞추기(glass tube rate)의 5가지의 게임을 통해 이루어지며 신체 압력중심점을 이동하여 체중지지와체 중이동을 유도한다. 훈련시간은 총 30 분으로 1 게임당 5 분의 훈련시 간과 1분의 휴식시간을 제공한다(Figure 1).

\section{2) 기능적 체중지지 훈련}

기능적 체중지지 훈련 그룹은 Eng 등ㄹㅇㅇㅢ 연구를 바탕으로 F1, F2, F3 3 가지로 구성된 발판 위에 각 순서에 맞는 동작을 양측 또는 편측으로 체중이동을 통해 5 가지의 과제 지향적 체중지지 훈련이 가능하도록 설계된 기능적인 체중지지훈련을 제공하였으며, 훈련 시 과제의 순 응을 최소화 하기 위해 무작위 임의 훈련을 실시하였다(Figure 2).

\section{3. 측정방법}

\section{1) 표면근전도시스템}

다리 근활성도를 측정하기 위해 MP100 표면근전도 시스템(Biopac System Inc, USA)을 이용하였고, 여기에서 전환된 디지털 신호는 개인 용 컴퓨터에서 Acqknowledge 3.91 소프트웨어를 이용하여 자료 처리 하였다. 표면근전도 신호에 대한 피부저항을 최소화하기 위해 부착 부위의 털을 제거하고 가는 사포로 3-4회 문질러 피부각질층을 제거 한 후, 소독용 알코올 솜으로 피부를 깨끗이 하였다. 부착 근육은 넙 

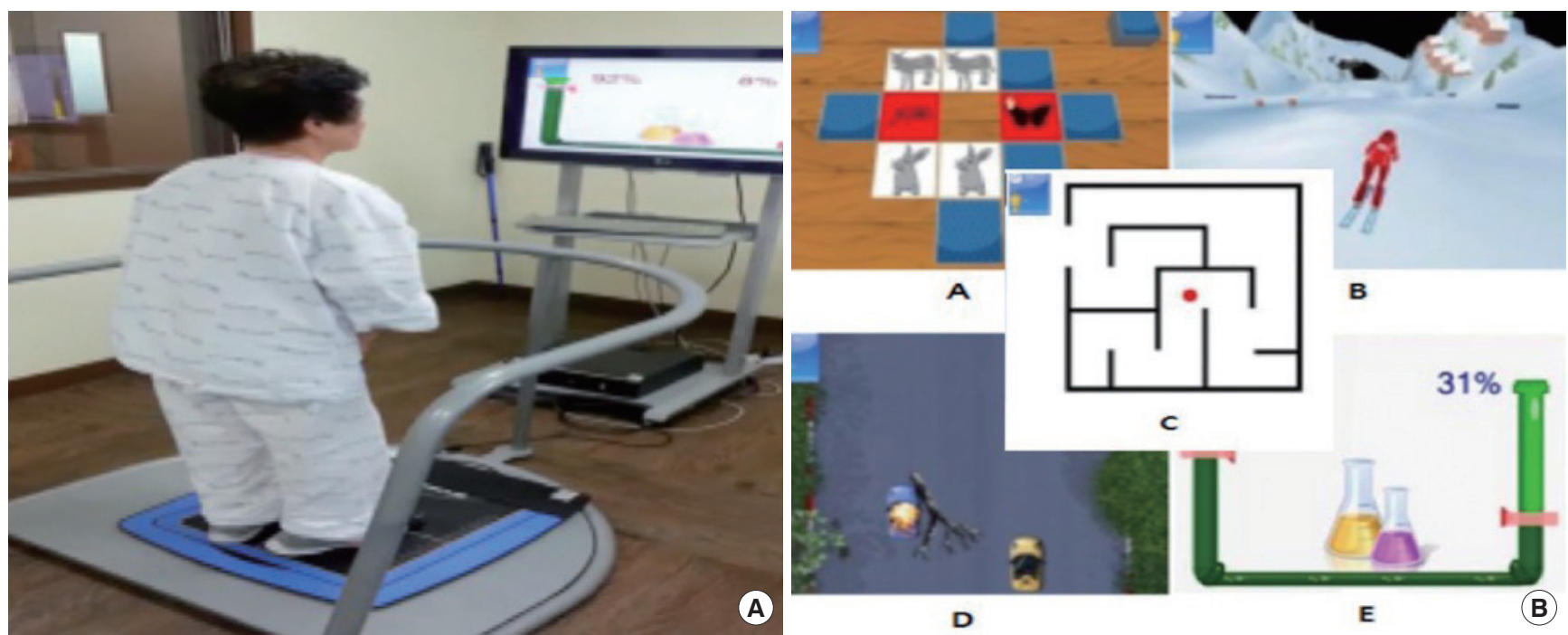

Figure 1. (A) Game based weight-bearing training system. (B) Game Program.

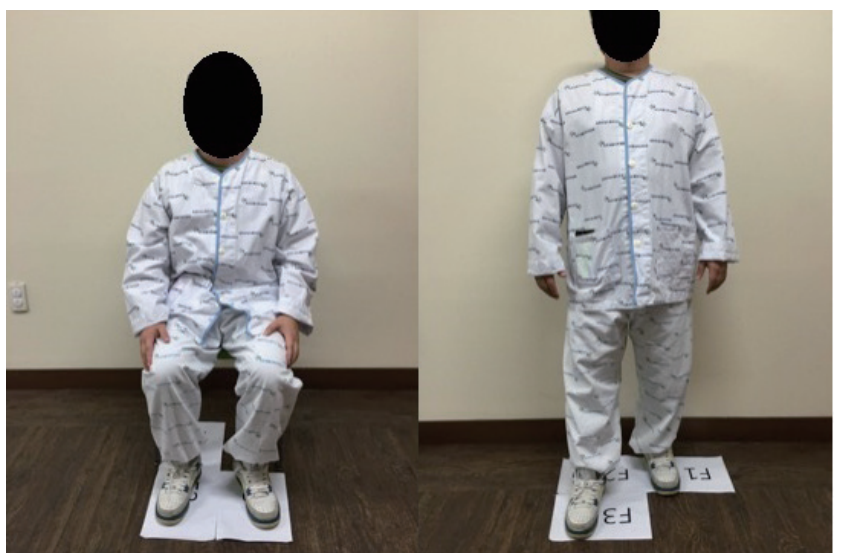

Figure 2. Functional weight-bearing training system.

다리곧은근, 넙다리두갈래근, 앞정강근, 장딴지근에 부착하였고 이 극전극은 각 근육의 근힘살(muscle belly)에 근섬유의 방향과 평행하 게 부착하였다. 표본추출률(sampling rate)은 $1,024 \mathrm{~Hz}$ 로 설정하였고, 잡음을 최소화하기 위해 대역 여과 필터(notch filter)는 $60 \mathrm{~Hz}$, 대역 통 과 필터(band pass filter) 30-500 Hz로 설정하였으며 수집된 신호는 RMS 처리하였다. ${ }^{22}$

\section{2) 근활성도의 표준화}

본 연구에서 근활성도를 표준화하기 위해 특정 동작의 근수축을 기 준 수축(reference voluntary contraction, RVC)으로 삼아 이를 기준으 로 표준화하는 \%기준수축(\%RVC)방법을 이용하였다. 기준수축은 반 웅크리기(semi-squat) 자세를 5 초 유지하는 동안 마비측 하지의 근 활성도를 측정하여 처음과 마지막 1 초씩을 제외한 3 초의 신호를 분 석하여 RVC값을 산출하였고, 앉은 자세에서 일어나기 동안 마비측
다리의 근활성도 값과 비교하여 \%RVC값을 산출하였다. 근활성도의 자료는 3 회 측정하여 얻은 결과의 평균값을 이용하였다.

\section{3) 균형측정시스템}

균형능력을 측정하기 위해 Biorescue (RM Ingenierie, Rodez, France)를 이용하였다. Biorescue는 정적균형, 동적균형, 체중지지율, 압력중심의 이동면적 등 균형능력의 정량적인 측정이 가능하며 본 연구에서는 안정성 한계(limited of stability, LOS)를 측정하였다. 대상자는 선 자세 에서 안정성을 유지할 수 있는 최대범위를 측정하였으며 발목전략을 이용하여 모니터에 제시되는 8 개의 방향으로 압력중심을 이동시켜 중심점에 대한 이동거리를 바탕으로 면적을 산출하였다. 모든 측정 은 모니터를 통해 측정방법에 대한 영상을 제공하여 충분한 설명을 하였으며, 자료는 3 회 측정하여 얻은 결과값의 평균값을 이용하였다.

\section{4. 자료분석}

측정된 자료는 Window 용 SPSS 18.0을 이용하여 통계처리 하였으며, 두 그룹 간의 동질성 검증을 위해 독립표본 t-검정(independent t-test) 을 시행하였고, 중재방법에 따른 그룹 간 다리 근활성도와 균형능력 차이를 검증하기 위해 공분산분석(analysis of covariance, ANCOVA) 을 이용하여 분석하였다. 통계학적 유의수준은 $\alpha=0.05$ 로 하였다.

\section{결 과}

\section{1. 그룹 간 다리 근활성도 비교}

중재 전후 넙다리곧은근과 넙다리두갈래근의 그룹 간 근활성도 비교 에서 그룹 I은 그룹 II와 비교하여 유의한 차이를 보였다 $(\mathrm{p}<0.05)(\mathrm{Ta}-$ 
Table 2. Comparison of lower extremity muscle activation between groups

(Unit: \%)

\begin{tabular}{|c|c|c|c|c|c|c|}
\hline & \multicolumn{2}{|c|}{ Group I $(n=15)$} & \multicolumn{2}{|c|}{ Group ॥ $(n=15)$} & \multirow{2}{*}{$\mathrm{F}$} & \multirow{2}{*}{$\mathrm{p}$} \\
\hline & Pre & Post & Pre & Post & & \\
\hline RF & $29.46 \pm 4.15$ & $38.17 \pm 3.27$ & $28.89 \pm 5.06$ & $34.78 \pm 3.87$ & 4.122 & $0.048 *$ \\
\hline $\mathrm{BF}$ & $25.18 \pm 3.87$ & $29.27 \pm 4.19$ & $24.76 \pm 4.11$ & $27.81 \pm 3.92$ & 6.231 & $0.046^{*}$ \\
\hline TA & $27.20 \pm 4.67$ & $34.46 \pm 3.81$ & $28.46 \pm 4.89$ & $33.81 \pm 4.26$ & 15.362 & $<0.001^{+}$ \\
\hline GCM & $27.13 \pm 3.88$ & $35.11 \pm 3.14$ & $26.71 \pm 3.73$ & $32.67 \pm 3.41$ & 19.984 & $<0.001^{+}$ \\
\hline
\end{tabular}

Group I, game based weight-bearing training (GBWBT); Group II, functional weight-bearing training (FWBT).

$R F$, rectus femoris; $B F$, bicepcs femoris; $T A$, tibialis anterior; $G C M$, gastrocnemius.

${ }^{*} p<0.05 ;{ }^{\dagger} p<0.001$.

Table 3. Comparison of balance ability between groups

(Unit: $\left.\mathrm{cm}^{2}\right)$

\begin{tabular}{|c|c|c|c|c|c|c|}
\hline & Gro & $=15)$ & Grou & $7=15)$ & ᄃ & 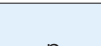 \\
\hline & Pre & Post & Pre & Post & $r$ & $\rho$ \\
\hline LOS & $141.18 \pm 28.68$ & $148.56 \pm 29.84$ & $139.87 \pm 28.45$ & $144.34 \pm 30.57$ & 22.54 & $<0.001^{*}$ \\
\hline
\end{tabular}

Group I, game based weight-bearing training (GBWBT); Group II, functional weight-bearing training (FWBT).

LOS, limited of stability.

${ }^{\star} p<0.001$.

ble 2). 중재 전후 앞정강근과 장딴지근의 그룹 간 근활성도 비교에서 그룹 I은 그룹 II와 비교하여 유의한 차이를 보였다 $(\mathrm{p}<0.001)$ (Table 2).

\section{2. 그룹 간 균형능력 비교}

그룹 간 중재 전후 균형능력 비교 결과, 그룹 I은 그룹 II와 비교하여 균형능력의 유의한 차이를 보였다 $(\mathrm{p}<0.001)$ (Table 3).

\section{고 찰}

본 연구는 뇌졸중 환자 30 명을 대상으로 게임 기반 체중지지훈련이 다리 근활성도와 균형능력에 미치는 영향을 알아본 결과 게임 기반 체중지지 훈련 그룹이 기능적 체중지지 훈련 그룹과 비교하여 중재 전후 다리 근활성도와 균형능력의 유의한 향상을 보였다.

Song 등 23 은 뇌졸중으로 인한 반마비 환자 27 명을 대상으로 게임기 반 가상현실 훈련 실험군(14명)과 일반적인 재활훈련 대조군(13명)으 로 나누어 5 주 동안 주 5 회 중재한 결과 실험군이 상지 기능 및 어깨 관절 바깥돌림, 안쪽돌림 근력과, 시.지각 기능에 유의한 향상을 보 였다. 본 연구에서도 게임 기반 체중지지 훈련 그룹과 기능적 체중지 지 훈련 그룹을 비교한 결과 게임 기반 체중지지 훈련 그룹에서 다리 근활성도에 유의한 차이를 보였다. 선행연구와 비교하여 훈련기간과, 훈련 방법에는 차이가 있지만 근활성도를 향상시키는 동일한 결과는 게임기반 체중지지 훈련이 뇌졸중 환자의 근활성도를 향상을 위해 필요하다는 것을 뒷받침 해줄 수 있다.

Cho와 Shin²은 노인 32명을 대상으로 wii-fit을 이용한 게임 기반 균형 훈련 실험군(17명)과 일상생활동작 훈련 대조군(15명)으로 나
누어 8 주 동안 주 3 회 중재한 결과 실험군이 앞정강근과 장딴지근의 근활성도에 유의한 향상을 보였다. 선행연구와 비교하여 연구 대상 자에 차이가 있지만 게임 기반 훈련을 통해 다리 근활성도에 유의한 향상을 보이는 동일한 결과를 보였다. 뇌졸중 환자의 기능향상을 위 해서는 과제지향적 훈련과 외재적.내재적 되먹임이 운동학습과 운 동조절에 효율적이라고 하였다. ${ }^{25}$ 또한 게임 기반 훈련은 시각 청각 적 생체 되먹임의 제공과 게임을 통한 과제지향적 훈련 및 반복적 훈 련이 제공되며, 환자의 동기부여를 이끌어 낼 수 있기 때문에 다리 근 활성도 향상에 효과적인 것으로 생각된다.

뇌졸중 환자는 자세 동요의 증가와 안정성 한계의 감소와 같은 균 형능력의 저하를 보이며, ${ }^{26,27}$ 뇌졸중 환자의 자세조절은 넙다리네갈 래근, 뒤넙다리근, 장딴지근, 앞정강근의 근력과 높은 상관관계를 보 고하였다. ${ }^{28}$

Cheng 등 29 은 뇌졸중으로 인한 반마비 환자 52 명을 대상으로 일반 적인 재활치료와 율동적인 시각적 되먹임 체중이동 훈련 실험군(28 명)과 전통적인 뇌졸중 재활 프로그램을 이용한 균형 훈련 대조군 (24명)으로 나누어 3 주 동안 주 5 회 중재한 후 그룹 간 비교 결과 동적 균형 능력에 유의한 향상을 나타내었다. 또한 Srivastava 등 ${ }^{30}$ 은 뇌졸 중 환자 40 명을 대상으로 압력감각을 이용한 시각적 되먹임 균형 훈 련을 4 주 동안 주 5 회 중재한 결과 버그 균형평가와 안정성 한계, 보행 속도, 바델지수(Barthel index)의 유의한 향상을 보였다. 하지만 Walker 등 ${ }^{31}$ 은 급성기 뇌졸중 환자 30 명을 대상으로 압력중심에 대한 정보를 시각적 되먹임을 이용하여 체중이동 훈련 실험군(16명)과 치료사의 구두 지시나 자극을 통해 체중이동 훈련 대조군(14명)으로 나누어 5 주 동안 주 3 회 중재한 후 그룹 간 비교 결과 버그 균형 평가와 정적 균 
형 능력, 일어나서 가기 검사(Timed “UP \& GO" Test, TUG)에서 유의 한차이가 없었다.

본 연구에서는 게임기반 체중지지 훈련그룹이 기능적 체중지지훈 련 그룹과 비교하여 중재 전후 안정성 한계에 유의한 증가를 보여 선 행연구와 부분 일치하였다. 실험군이 균형능력의 향상시킨 동일한 결 과는 체중지지를 통한 압력중심에 대한 정보의 시.청각적 되먹임의 제공 32 이 균형 능력을 향상시킨 것으로 생각된다. 선행연구와 부분 일 치한 이유는 선행연구는 주 3 회 중재를 제공하였으나, 균형능력 향상 을 위한 많은 연구들이 주 5 회의 강도 높은 훈련(intensive mass practice)을 중재하였다. ${ }^{33}$ 그러므로 균형능력의 향상을 위해서는 주 5 회의 강도 높은 훈련을 중재해야 할 것으로 생각된다. 또한 선행연구에서 는 급성기 환자만을 대상자로 선정한 결과 천장효과-(ceiling effect)로 인하여, ${ }^{34}$ 실험 결과가 왜곡되어 유의하지 않은 결과를 보인 것으로 사료된다.

$$
\text { 본 연구의 제한점은 대상자 수가 적고, 특정 지역에서의 대상자 선 }
$$
정으로 모든 뇌졸중 환자에게 일반화하기에는 어려움이 있으며, 향 후 본 연구를 바탕으로 뇌졸중 환자에게 게임기반 체중지지 훈련이 보행과 삶의 질에 미치는 영향에 대한 추가적인 연구가 필요할 것으 로 사료된다.

\section{ACKNOWLEDGEMENTS}

The Research has been conducted by the Research Grant of Sehan University in 2015.

\section{REFERENCES}

1. Hackett ML, Anderson CS. Predictors of depression after stroke: A systematic review of observational studies. Stroke. 2005;36(10):2296-301.

2. Arene N, Hidler J. Understanding motor impairment in the paretic lower limb after a stroke: A review of the literature. Top Stroke Rehabil. 2009; 16(5):346-56.

3. Kligyte I, Lundy-Ekman L, Medeiros JM. Relationship between lower extremity muscle strength and dynamic balance in people post-stroke. Medicina (Kaunas). 2003;39(2):122-8.

4. Daneshjoo A, Mokhtar AH, Rahnama N et al. The effects of comprehensive warm-up programs on proprioception, static and dynamic balance on male soccer players. PLoS One. 2012;7(12):e51568.

5. Geiger RA, Allen J B, O'Keefe J et al. Balance and mobility following stroke: effects of physical therapy interventions with and without biofeedback forceplate training. Phys Ther. 2001;81(4):995-1005.

6. Choi AY, Cho WS. The effects of mechanical horseback riding exercise on the dynamic balance in patients with cerebral infarction. J Kor Phys Ther. 2014;26(2):123-9.

7. van Nes IJ, Nienhuis B, Latour H et al. Posturographic assessment of sit- ting balance recovery in the subacute phase of stroke. Gait Posture. 2008;28(3):507-12.

8. Yang DJ, Park SK, Kang JI et al. Effects of changes in postural alignment on foot pressure and balance of patients with stroke. J Kor Phys Ther. 2014;26(4):226-33.

9. Geurts AC, de Haart M, van Nes IJ et al. A review of standing balance recovery from stroke. Gait Posture. 2005;22(3):267-81.

10. Park JH, Kim YM, Lee NK. The effects of repetitive sit-to-stand training with a paretic-side asymmetrical foot position on the balance of chronic stroke subjects. J Kor Phys Ther. 2015:27(3):169-73.

11. Goldie PA, Matyas TA, Evans OM et al. Maximum voluntary weightbearing by the affected and unaffected legs in standing following stroke. Clin Biomec. 1996;11(6):333-42.

12. Sharp SA, Brouwer BJ. Isokinetic strength training of the hemiparetic knee: Effects on function and spasticity. Arch Phy Med Rehabil. 1997; 78(11):1231-6.

13. Verheyden G, Nieuwboer A, Mertin J et al. The Trunk impairment scale: a new tool to measure motor impairment of the trunk after stroke. Clin Rehabil. 2004;18(3):326-34.

14. Cheng PT, Wu SH, Liaw MY et al. Symmetrical body-weight distribution training in stroke patients and its effect on fall prevention. Arch Phys Med Rehabil. 2001;82(12):1650-4.

15. Tsaklis PV, Grooten WJ, Franzén E. Effects of weight-shift training on balance control and weight distribution in chronic stroke: A pilot study. Top Stroke Rehabil. 2012;19(1):23-31.

16. Holden MK. Virtual environments for motor rehabilitation: Review. Cyberpsychol Behav. 2005;8(3):187-211.

17. Weiss PL, Rand D, Katz N et al. Video capture virtual reality as a flexible and effective rehabilitation tool. J Neuroeng Rehabil. 2004 Dec 20;1(1): 12.

18. Lee DK, Kim EK, Kim YN et al. Effects of a virtual reality training program on balance and lower muscular strength of parkinson's disease patients. J Kor Phys Ther. 2013;25(2):96-102.

19. Deutsch JE, Robbins D, Morrison J. Wii-based compared to standard of care balance and mobility rehabilitation for two individuals post-stroke. IEEE. 2009;june:117-20.

20. Betker AL, Desai A, Nett C et al. Game-based exercises for dynamic short-sitting balance rehabilitation of people with chronic spinal cord and traumatic brain injuries. Phys Ther. 2007;87(10):1389-98.

21. Eng JJ, Chu KS. Reliability and comparison of weight-bearing ability during standing tasks for individuals with chronic stroke. Arc Phys Med Rehabil. 2002;83(8):1138-44.

22. Park SK, Kim JH. Effects of EMG-biofeedback training on total knee replacement patients' lower extremity muscle activity and balance. J Kor Phys Ther. 2013;25(2):81-7.

23. Song CH, Seo SM, Lee KJ et al. Video game-based exercise for upperextremity function, strentgth, visual perception of stroke patients. Journal of Special Education \& Rehabilitation Science. 2011;50(1):155-80.

24. Cho GH, Shin HS. The effect of virtual reality training on lower extremity muscle activation in elderly. J Korean Soc Phys Med. 2014;9(1):55-62.

25. Lee GH. Effects of virtual reality exercise program on balance in multiple sclerosis patients. J Kor Phys Ther. 2015:27(1):61-7.

26. de Haart M, Geurts AC, Huidekoper SC et al. Recovery of standing balance in postacute stroke patients: A rehabilitation cohort study. Arch 
Phys Med Rehabil. 2004;85(6):886-95.

27. Park SK, Park SH. The effects of water-based exercise on physiological cost Index and balance in stroke patients. J Kor Phys Ther. 2014;26(6): 411-7.

28. Bleyenheuft C, Bleyenheuft Y, Hanson P et al. Treatment of genu recurvatum in hemiparetic adult patients: A systematic literature review. Ann Phys Rehabil Med. 2010;53(3):189-99.

29. Cheng PT, Wang CM, Chung CY et al. Effects of visual feedback rhythmic weight-shift training on hemiplegic stroke patients. Clin Rehabil. 2004;18(7):747-53.

30. Srivastava A, Taly AB, Gupta A et al. Post-stroke balance training: Role of force platform with visual feedback technique. J Neurol Sci. 2009;
287(1):89-93.

31. Walker C, Brouwer BJ, Culham EG. Use of visual feedback in retraining balance following acute stroke. Phys Ther. 2000;80(9):886-95.

32. Park SD, Song HS, Kim JY et al. Comparison of balance and fall efficacy of virtual reality program in elderly women with fall experience. J Kor Phys Ther. 2014;26(6):430-5.

33. Langhorne P, Coupar F, Pollock A. Motor recovery after stroke: A systematic review. Lancet Neurol. 2009;8(8):741-54.

34. Sivan M, O'Connor RJ, Makower S et al. Systematic review of outcome measures used in the evaluation of robot-assisted upper limb exercise in stroke. J Rehabil Med. 2011;43(3):181-9. 